\title{
A double-blind trial of long-term anticoagulant treatment after myocardial infarction
}

Citation for published version (APA):

Loeliger, E. A., Hensen, A., Kroes, F., van Dijk, L. M., Fekkes, N., de Jonge, H., \& Hemker, H. C. (1967). A double-blind trial of long-term anticoagulant treatment after myocardial infarction. Journal of Internal Medicine, 182(5), 549-566. https://doi.org/10.1111/j.0954-6820.1967.tb10881.x

Document status and date:

Published: 01/01/1967

DOI:

10.1111/j.0954-6820.1967.tb10881.x

Document Version:

Publisher's PDF, also known as Version of record

\section{Please check the document version of this publication:}

- A submitted manuscript is the version of the article upon submission and before peer-review. There can be important differences between the submitted version and the official published version of record.

People interested in the research are advised to contact the author for the final version of the publication, or visit the DOI to the publisher's website.

- The final author version and the galley proof are versions of the publication after peer review.

- The final published version features the final layout of the paper including the volume, issue and page numbers.

Link to publication

\footnotetext{
General rights rights.

- You may freely distribute the URL identifying the publication in the public portal. please follow below link for the End User Agreement:

www.umlib.nl/taverne-license

Take down policy

If you believe that this document breaches copyright please contact us at:

repository@maastrichtuniversity.nl

providing details and we will investigate your claim.
}

Copyright and moral rights for the publications made accessible in the public portal are retained by the authors and/or other copyright owners and it is a condition of accessing publications that users recognise and abide by the legal requirements associated with these

- Users may download and print one copy of any publication from the public portal for the purpose of private study or research.

- You may not further distribute the material or use it for any profit-making activity or commercial gain

If the publication is distributed under the terms of Article $25 \mathrm{fa}$ of the Dutch Copyright Act, indicated by the "Taverne" license above, 


\title{
Acta Medica Scandinavica. Vol. 182, fasc. 5, 1967
}

From the Haematology Section of the Department of Internal Medicine (Head: J. Mulder, M. D. $\dagger$ ), the Department of Cardiology (Head: H. A. Snellen, M. D.), University Hospital,

Leyden, and the Thrombosis Service (Head: E. A. Loeliger, M. D.), Leyden,

The Netherlands

\section{A Double-blind Trial of Long-term Anticoagulant Treatment after Myocardial Infarction}

\author{
By \\ E. A. Loeliger, A. Hensen, F. Kroes, L. M. van Dijk, N. Fekkes, \\ H. DE Jonge And H. C. Hemker
}

After 1960 increasing opposition to longterm anticoagulant treatment for coronary thrombosis in our own as well as in other countries $(4,8,14,16,18,26)$ called for re-assessment of the value of treatment, given for an unlimited period to a steadily increasing number of patients controlled at our Thrombosis Service. The value of a treatment given for longer than one year had become especially doubtful. Hence in 1963 we decided to undertake a double-blind clinical trial including all our patients treated for longer than one year after cardiac infarction. Fortunately the condition considered crucial for successful anticoagulant treatment, i.e. effective hypocoagulability, could be achieved through the choice of a suitable drug $(7,10,29)$ and particularly through the facilities put at our disposal by the Netherlands Thrombosis Service (20, 22, 23). This paper is the final report of the trial.

Submitted for publication April 4, 1967.

\section{Material and methods}

In Jan. 1964, 417 patients treated with coumarin drugs for more than one year after a clinically and electrocardiographically proven cardiac infarction were being cared for by the Thrombosis Service of Leyden. Before grouping, 150 of these patients were excluded from the study for the reasons indicated in table $\mathrm{I}$.

No males younger than 45 , or older than 75 years, and no females were included in the study, the number of the latter being too small to satisfy requirements for separate statistical evaluation. Immobilized patients were not admitted because when not treated with coumarin drugs these patients are known to run a high risk of thromboembolic complications.

The remaining 267 patients, all of whom had proven their willingness and suitability for treatment during the year(s) before admission to the study, were divided into three age classes: $45-54,55-64$, and $65-$ 74 years. The patients in each class were subdivided into two chronological groups by alternating allocation according to the date of infarction, i.e. of admission to the Thrombosis Service. The decision as to 
TABLE I. Numbers of patients excluded from the trial, arranged according to reason for exclusion

Reason for exclusion

Number of patients excluded

Before After grouping

grouping

Phenpro- Placebo Total

coumon

Sex (women)

62

19

Age $<45$ years

$>75$ years

On coumarin drug other than phenprocoumon

Hypertension $(>200>120)$

Immobilization

Atrial fibrillation

Malignant tumour

Other medical reasons

Adequate supervision not feasible

Psychological reasons

Inappropriate inclusion

Death

Total

\section{4}

1

20

1

1

4

2

7

\begin{tabular}{rrrr} 
& 1 & 3 & 4 \\
& 1 & 1 & 2 \\
\hline 150 & 6 & 11 & 167
\end{tabular}

TABle II. Data concerning comparability of the two groups of patients treated with placebo and phenprocoumon, respectively

\begin{tabular}{|c|c|c|c|c|c|c|c|c|}
\hline & \multicolumn{4}{|c|}{ Phenprocoumon } & \multicolumn{4}{|l|}{ Placebo } \\
\hline . & $45-54$ & $55-64$ & $65-75$ & Total & $45-54$ & $55-64$ & $65-75$ & Total \\
\hline Number of patients & 34 & 57 & 37 & 128 & 31 & 60 & 31 & 122 \\
\hline Mean age & 50.5 & 59.4 & 67.5 & 59.4 & 50.35 & 59.4 & 69.1 & 59.6 \\
\hline $\begin{array}{l}\text { Mean "pre-trial" anti- } \\
\text { coagulant period (mos) }\end{array}$ & 35.4 & 37.0 & 46.8 & 39.4 & 39.2 & 39.3 & 44.7 & 40.6 \\
\hline Diabetes mellitus & 2 & 1 & 1 & 4 & 0 & 1 & 0 & 1 \\
\hline Hypertension $(>180$ & & & & & & & & \\
\hline$>100)$ & 3 & 8 & 4 & 15 & 1 & 7 & 2 & 10 \\
\hline $\begin{array}{l}\text { Re-infarction during "pre- } \\
\text { trial" anticoagulant period }\end{array}$ & 1 & 0 & 0 & 1 & 1 & 2 & 0 & 3 \\
\hline $\begin{array}{l}\text { Re-infarction as indica- } \\
\text { tion for long-term treatment }\end{array}$ & t 3 & 6 & 4 & 13 & 0 & 5 & 1 & 6 \\
\hline
\end{tabular}

which group should be treated with placebo was made by lot for each class separately. As a result of this procedure, 134 patients would have been treated with phenpro- coumon and 133 with placebo. However, reexamination of the patients revealed four inappropriate inclusions (two with insufficient evidence of cardiac infarction, 
TABLE III. Comparability of the two groups of patients according to length of the pre-trial anticoagulant treatment

Length of anticoagulant treatment before trial (mos)

$12-24-36-48-60-72-84-96-108-120$

\begin{tabular}{lrrrrrrrrl} 
Phenprocoumon & 39 & 23 & 23 & 16 & 13 & 10 & 2 & 1 & 1 \\
Placebo & 36 & 24 & 19 & 18 & 17 & 5 & 3 & - & - \\
\hline
\end{tabular}

and two females), two patients suffering from severe hypertension, and four cases of atrial fibrillation. Two patients died, and five patients became bedridden between classification and the start of the trial, resulting in a total of 17 drop-outs (columns 2 and 3 of table I). Hence, 250 patients finally entered the trial: 122 patients in the placebo group and 128 patients in the phenprocoumon group. The period during which the patients entered the trial lasted from the end of March until the beginning of May 1964.

The criteria applied for comparability of the two groups are indicated in tables II and III. Table III, which gives the number of patients in the two groups according to the length of the pre-treatment period, further illustrates the similarity of the two groups.

At the start of the trial all patients were told that they would be treated with a new preparation, similar in its action to phenprocoumon. The tablets, given us by $\mathrm{F}$. Hoffman-La Roche, Basel, were distributed by the Thrombosis Service. The placebo tablet consisted of saccharum lactis. The phenprocoumon and placebo tablets were identical in shape and colour. To prevent mistakes, the letter $\mathrm{M}$ was not printed on the placebo tablets. The therapeutic regimen was the same in patients of both groups except for the anticoagulant drug. Vitamin $K_{1}$ prophylaxis for tooth extraction was given in all patients. Two of us $(\mathrm{AH}$ and NF) were in charge of the dosage of phenprocoumon and placebo. The dose of the coumarin drug was prescribed on the basis of the results of the coagulation test, the dose of placebo according to that of phenprocoumon in the preceeding year. As a security-check a calendar with indication of the daily dosage was mailed to the patients after each coagulation test. The patients were asked to cross out each dose of the medicament as soon as it was taken. The mean daily dose of phenprocoumon was $2.8 \mathrm{mg}$.

Attending physicians - general practitioners and specialists-had given their full consent to the trial. They were not informed about the kind of treatment and they received, instead of the result of the coagulation test, a monthly reminder that the patient had been checked for the long-term anticoagulant treatment. In case of re-infarction, other kinds of important cardiovascular deterioration, appearance of dysbasia intermittens, cerebrovascular accident, or venous thrombosis and, lastly, in case of bleeding, the attending physician contacted one of us (EAL). The decision as to the type of treatment was made before the patient's status in the trial was known; if the decision was "new indication for anticoagulant treatment", he was removed from the trial.

The main criteria for determining the value of the therapy were death-rate and rate of re-infarction. The diagnosis reinfarction based upon clinical, electrocardiographical and if available, biochemical investigations, has been made by two different cardiologists (FK and LMvD). In addition, the rate of other cardiovascular complications was determined. Finally, 14 months after the beginning of the trial an investigation into complaints was made.

At the end of Aug., 1965, the trial was 


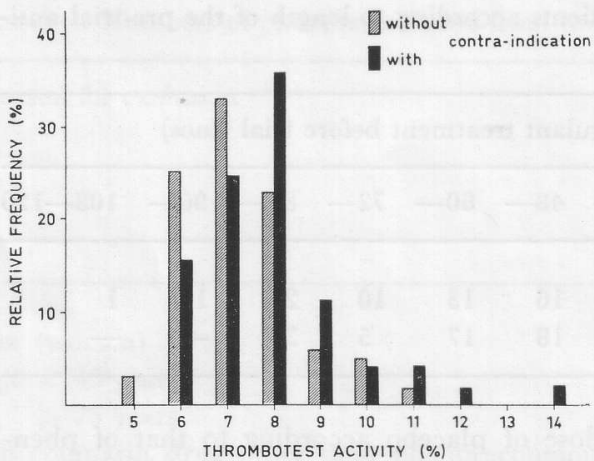

Fig. 1. Diagram of intensity and stability of hypocoagulability as measured by means of thrombotest activity. The values are grouped in classes of $1 \%$. Solid columns represent values found in patients without contraindications, and hatched columns those found in the patients with "relative" contra-indications (see text).

TABLE IV. Illustration of intensity and stability of treatment: 696 thrombotest percentages (a representative sample of the phenprocoumon group) were classified as shown: $94.1 \%$ of the values lay below $15 \%$, and $87.3 \%$ between $5 \%$ and $15 \%$

\begin{tabular}{ll}
$\begin{array}{l}\text { Thrombotest, value-classes } \\
(\%)\end{array}$ & $\begin{array}{l}\text { No of values } \\
(/ \text { class, } \%)\end{array}$ \\
\hline & \\
$<5$ & 6.8 \\
$5-10$ & 68.2 \\
$>10-15$ & 19.1 \\
$>15-20$ & 4.0 \\
$>20-25$ & 1.2 \\
$>25-30$ & 0.4 \\
$>30$ & 0.3 \\
\hline
\end{tabular}

finished. All patients were switched to regular phenprocoumon therapy. Tablets were no longer supplied gratuitously by the Thrombosis Service; the patients had to buy them on prescription.

The coagulation check consisted of thrombotest performed on venous blood. In cases with no contra-indication we tried to attain values of thrombotest within the range of $5 \%-10 \%$, whereas in cases with relative contra-indications (almost $50 \%$ of the patients displayed relative contraindications such as age $>65$, hypertension, anamnestical cerebrovascular accident, cured gastric or duodenal ulcer) the corresponding range was $7 \%-13 \%$.

Fig. 1 and table IV demonstrate the intensity of the coumarin effect as assessed by thrombotest. For each of the 116 patients still in the trial after one year of treatment, six of the $12-18$ thrombotest values obtained during the first 12 months of the trial ( $=\mathrm{a}$ total of 696 values) were collected by taking the values of the first check of every 2-month period. The logarithm of these values was used for the calculation. The anti-log of the mean of the six logarithmic values was converted into \% TT and considered to be representative of the level achieved in the individual. In fig. 1 the individual average values for these 116 patients are distributed into classes of $1 \%$.

As fig. 1 shows, the 59 patients without contra-indications were more intensively treated than the 57 patients with relative contra-indications. The overall mean thrombotest activities were $7.5 \%$ and $8.2 \%$, respectively. The standard deviations of the individual means were $1.25 \%$ and $1.48 \%$, respectively, indicating that the stability of hypocoagulability was somewhat better in patients without contra-indications.

In addition, the variation of thrombotest activity in individual patients was calculated from the $116 \times 6$ values; the standard deviation of the individual thrombotest percentages was about $2.9 \%$.

Table IV, in which the 696 thrombotest values are classified according to activity in classes of $5 \%$, illustrates the intensity and stability of the treatment.

The thrombotest values of the eight "sudden deaths", two re-infarctions, and two important cardiovascular deteriorations during phenprocoumon treatment were analyzed separately. They do not differ from those found in the other patients either as to 
TABLE V. Classification of bleeding complications according to treatment, c.q. severity

\begin{tabular}{ll}
\hline $\begin{array}{l}\text { Phenpro- Placebo } \\
\text { coumon }\end{array}$ \\
\hline
\end{tabular}

No change in dosage 11

Temporary lowering of

dosage

6

Administration of

vitamin $\mathrm{K}_{1}$

Blood transfusion

1 Two nacrohaematurias, one subarachnoidal bleeding.

${ }^{2}$ Lethal intracerebral bleeding.

intensity or as to stability of the hypocoagulability.

The adequacy of the treatment was further assessed by calculating the bleeding frequency; tables V and VI show these results.

\section{Results}

Immediately after the beginning of the trial, a transitory increase of complaints in patients of both groups was observed. There was, however, no accumulation of cardiovascular complications either in the placebo or in the phenprocoumon group during this period. The results of the trial are summarized in table VII. Details of the 16 "sudden" deaths, 14 re-infarctions, and 15 other cardiovascular complications, are given in tables VIII, IX, and X.

Besides the patients referred to in tables IX and $\mathrm{X}$, all of whom were switched from placebo back to phenprocoumon, three other patients had to be removed from the trial, two suffer-
TABle VI. Classification of bleeding complications according to localization

\begin{tabular}{lll}
\hline Localization & $\begin{array}{l}\text { Phenpro- } \\
\text { coumon }\end{array}$ & Placebo \\
\hline Cutaneous & 5 & 0 \\
Nasopharyngeal & 7 & 5 \\
Intestinal & 1 & 1 \\
Urogenital & 2 & 0 \\
Intracranial & 1 & 1 \\
Subconjunctival & 1 & 0 \\
\hline
\end{tabular}

TABLE VII. Summary of the results

Phenpro- Placebo
coumon

$\begin{array}{lrr}\text { Number of patients } & & \\ \quad \text { April 1964 } & 128 & 122 \\ \quad \text { Aug. 1965 } & 112 & 81 \\ \text { Years of exposure to } & & \\ \text { risk } & 168 & 138 \\ \text { "Sudden" death } & 8 & 8 \\ \text { Re-infarction } & 2 & 112 \\ \begin{array}{l}\text { Important cardiac } \\ \text { deterioration }\end{array} & 1 & \\ \begin{array}{l}\text { Dysbasia intermittens } \\ \text { Cerebrovascular }\end{array} & 1 & 47 \\ \text { accident } & & \\ \begin{array}{l}\text { Venous thrombosis } \\ \text { Total cardiovascular }\end{array} & - & 12 \\ \text { complications } & 12 & 2 \\ \text { Severe bleeding } & & 35 \\ \text { complications } & { }^{2} 1 & \\ \text { Number of drop-outs } & 5 & 7\end{array}$

1 One death.

${ }^{2}$ Subarachnoidal bleeding, with complete recovery.

${ }^{3}$ Lethal intracerebral haemorrhage, already tabulated under cerebrovascular accident.

ing from venous thrombosis while on placebo and one displaying a subarachnoidal bleeding during phenprocoumon therapy. 
TABLE VIII. Data concerning patients who died "suddenly". The pre-treatment period is the time of phenprocoumon treatment before the start of the trial

\begin{tabular}{lllll}
\hline Pats & Age & $\begin{array}{l}\text { Pre-treatment } \\
\text { period (mos) }\end{array}$ & $\begin{array}{l}\text { Treatment } \\
\text { period (mos) }\end{array}$ & $\begin{array}{l}\text { Cardiac symp- } \\
\text { toms before death }\end{array}$ \\
\hline $\begin{array}{l}\text { Phemprocoumon } \\
\text { HCGT }\end{array}$ & 61 & 15 & 2 & No \\
JGS & 55 & 29 & 5 & Yes \\
BG v. M & 52 & 79 & 9 & No \\
G v. R & 64 & 50 & 9 & No \\
WJ & 55 & 52 & 11 & No \\
HW & 61 & 21 & 12 & No \\
JJT & 54 & 45 & 16 & No \\
PJ v. Z & 53 & 22 & 16 & No \\
Placebo & & & & Yes \\
J d. H & 71 & 24 & $25 / 30$ & No \\
KR v. R & 51 & 15 & 2 & Yes \\
A v.d. V & 51 & 64 & 6 & Yes \\
JK & 56 & 22 & 8 & Yes \\
GSW & 72 & 72 & 12 & No \\
R v. D & 57 & 65 & 13 & No \\
J v. K & 62 & 18 & 14 & No \\
JZ & 52 & 77 & & \\
\hline
\end{tabular}

${ }^{1}$ Diabetic.

Two patients, one treated with phenprocoumon and the other with placebo, who suffered a minor cerebrovascular accident that according to the consulting neurologist was neither an indication nor a contra-indication for anticoagulant treatment, remained in the trial. The same holds for a patient with signs of retinal ischaemia while on phenprocoumon.

The distribution of all cardiovascular accidents (deaths, re-infarctions, and other cardiovascular complications) over observation time and age groups is shown in fig. 2. Obviously, there is no correlation between incidence and observation time in either the phenprocoumon or the placebo patients. This may be seen even more clearly from fig. 3 , in which the incidence/observation time correlation is depicted cumulatively. On the other hand, there seems to be a correlation between incidence and age: during the $161 / 2$ months of observation, $18 \%$ of the patients of the youngest group displayed a cardiovascular accident, whereas $15 \%$ of the middle-aged and only $6 \%$ of the elderly patients did so. Statistiscally, this decline is significant at a $5 \%$ level in the placebo group, whereas no clear decline is to be seen in the phenprocoumon group.

Of the 25 patients suffering from reinfarction or some other cardiovascular deterioration who were put back to phenprocoumon, two died from cardiac 
TABLE IX. Data for patients suffering from myocardial infarction

\begin{tabular}{lllllll}
\hline Pats & Age & $\begin{array}{l}\text { Pre-treatment } \\
\text { period (mos) }\end{array}$ & $\begin{array}{l}\text { Treatment } \\
\text { period (mos) }\end{array}$ & $\begin{array}{l}\text { Criteria } \\
\text { Clin. }\end{array}$ & EGG & SLDH \\
\hline Phemprocoumon & & & & & & \\
P d. K & 55 & 45 & 4 & + & + & - \\
N v. S & 61 & 14 & 12 & + & + & + \\
Placebo & & & & & & \\
HC & 58 & 66 & 1 & + & + & - \\
WV & 60 & 70 & 1 & + & + & - \\
WS & 59 & 63 & 3 & + & + & - \\
J d. W & 64 & 31 & 7 & + & + & + \\
ANM & 49 & 43 & 8 & + & + & - \\
GLJK & 56 & 22 & 10 & + & + & + \\
PS & 47 & 17 & 12 & + & + & + \\
WMH & 47 & 24 & 13 & + & + & + \\
J v. W & 49 & 37 & 13 & + & + & - \\
JZ & 53 & 45 & 14 & + & + & + \\
WH & 61 & 52 & 28 & + & + & - \\
N v. R & 61 & 28 & & + & + \\
\hline
\end{tabular}

${ }_{1}^{1}$ Hypertension.

2 Patient confined to home died on 7 th day after infarction.

3 Diabetes.

$-=$ SLDH not investigated.

insufficiency. None displayed another cardiovascular accident during the further observation period until the end of the trial. On conventional statistical treatment of the results in table VII, the difference between the 33 cardiovascular accidents occurring in the placebo group (the two venous thromboses were excluded) and the 12 accidents occurring in the phenprocoumon group is significant at a $0.1 \%$ level; for recurrences (12:2) and other cardiovascular complications (13:2) the differences are significant at a $5 \%$ and $1 \%$ level, respectively. However, with the statistical approach applied by Bjerkelund (2) the differences both for recurrences and for other cardiovascular deteriorations are significant at a $1 \%$ level ( $\mathrm{P}$ recurrences $<0.005$; $\mathrm{P}$ cardiovascular deteriorations $<0.001)$. Bjerkelund's approach takes into account the fact that the size of the placebo group diminishes more rapidly than that of the phenprocoumon group; the total time of treatment (which can be defined as time of exposure to risk) for the placebo and the phenprocoumon groups amounted to 138 and 168 patient-years respectively.

Finally, in order to obtain more comparable figures, the rate $(\%)$ of the different types of accidents was calculated by dividing the number of accidents by the time of exposure to risk (in years), the resulting value being multiplied by 100. Table XI gives the results. 
TABLE X. Data for patients suffering from other cardiovascular complications

\begin{tabular}{cllll}
\hline Pats Age & $\begin{array}{l}\text { Pre- } \\
\text { treat- }\end{array}$ & $\begin{array}{l}\text { Treat- Cardiovascular } \\
\text { ment complications }\end{array}$ & Remarks \\
& ment & period & \\
& period & (mos) & \\
& & &
\end{tabular}

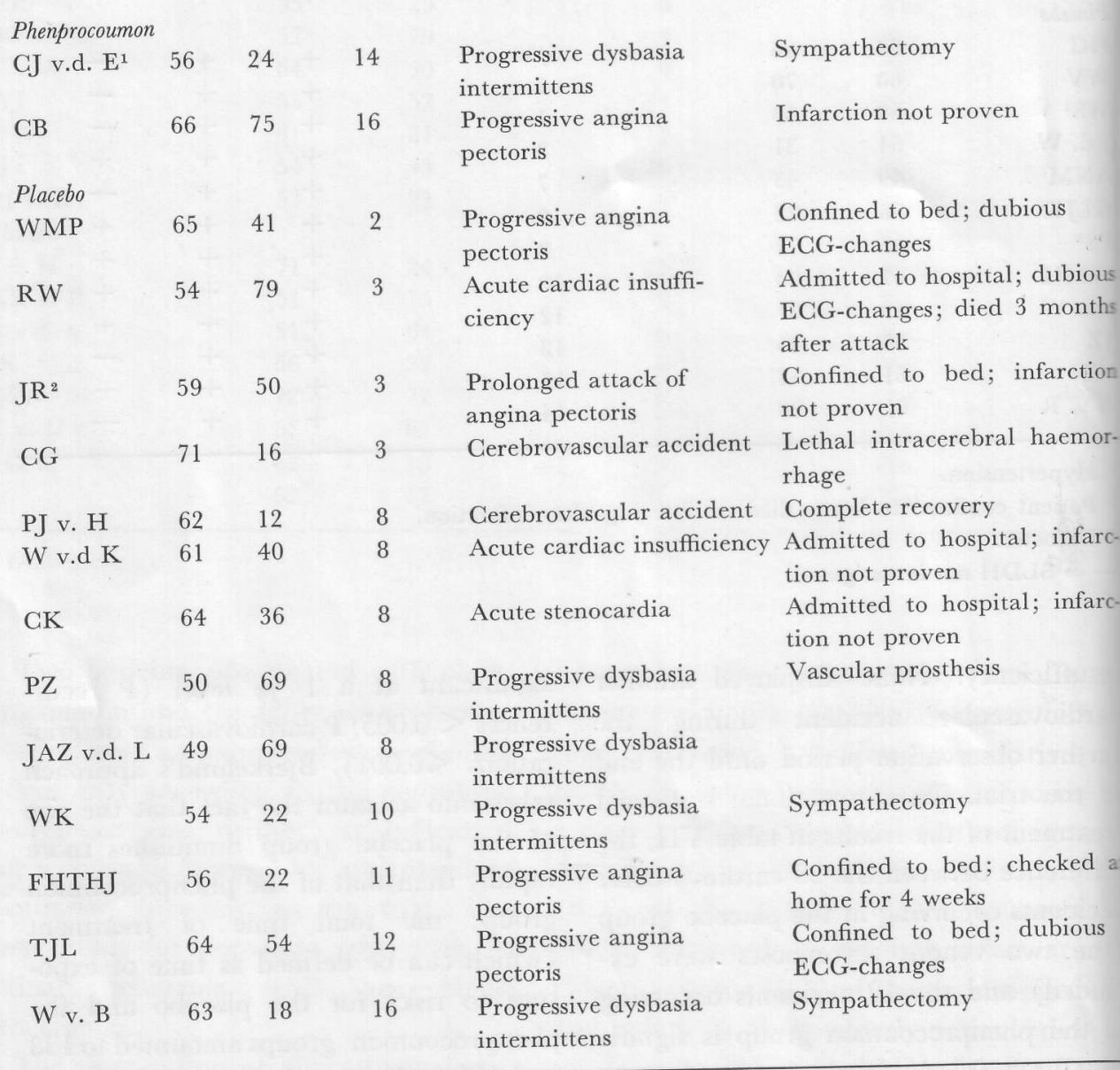

1 Diabetic.

2 Hypertension.

The death-rate, undoubtedly the main the phenprocoumon and $7.2 \%(10 / 13$ criterion for the success of anticoagulant $\times 100)$ in the placebo group. If we ad treatment, was $4.8 \%(8 / 168 \times 100)$ in to the length of exposure to risk the ob 


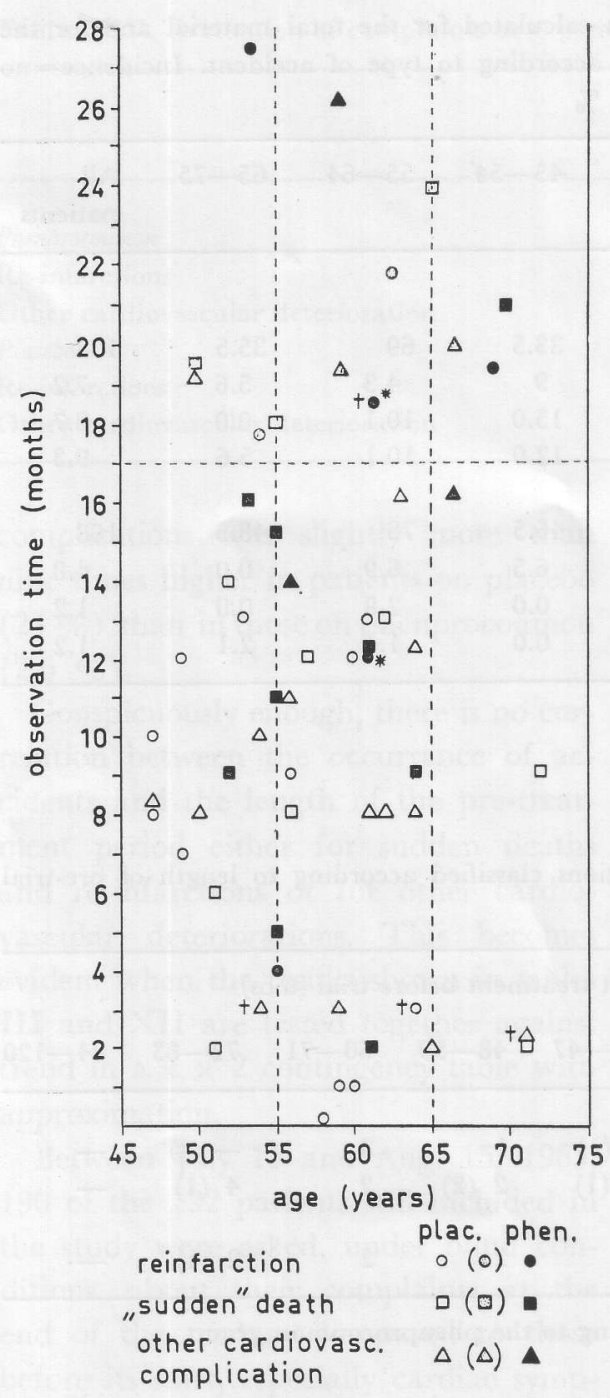

Fig. 2. Synopsis of cardiovascular accidents related to time of treatment (ordinate) and age (abscissa). After the end of the trial (horizontal dotted line) complications occurring in patients belonging to the former placebo group are represented by punctuated signs (* = same patient).

servation time of patients returned to phenprocoumon (14 years for placebo patients and two years for phenprocoumon patients) the respective

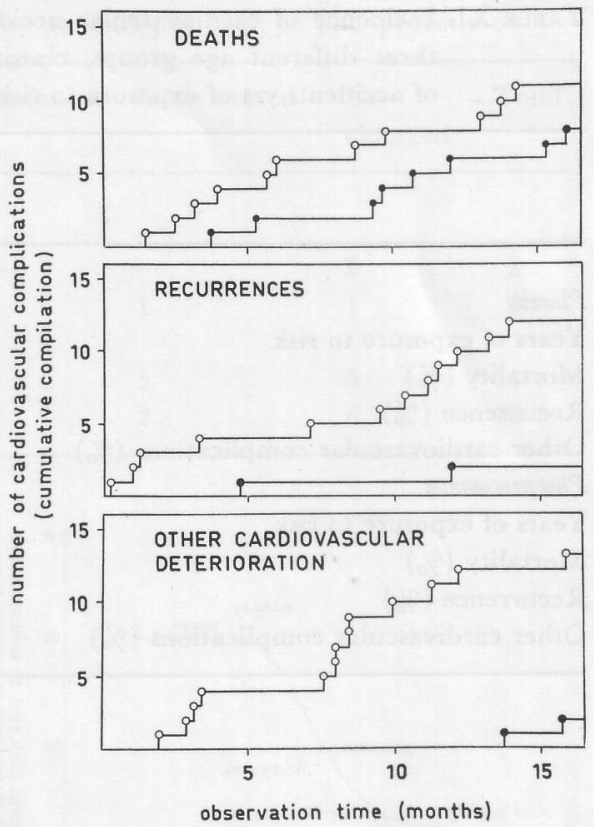

Fig. 3. Occurrence of cardiovascular complications related to observation time (cumulative compilation). In the figure depicting cardiovascular death rate there are included, besides the 16 sudden deaths, the two patients put back on phenprocoumon shortly before their death as well as the lethal cerebral hemorrhage in a patient belonging to the placebo group.

figures become $4.7 \%(8 / 170 \times 100)$ and $7.2 \%(11 / 152 \times 100)$. There appears to be no significant difference between the death-rate in the two groups considered in either way. The re-infarction rate, however, is distinctly higher in the placebo group than in the phenprocoumon group (8.7\% against $1.2 \%)$, the highest difference found in the youngest age-group (15\% against $0 \%$ ). A similar conclusion holds for the difference in incidence of other cardiovascular complications.

For the two younger age-groups taken together, the rate of the sum of reinfarctions and other cardiovascular 
TABLE XI. Incidence of cardiovascular accidents calculated for the total material and for the three different age groups, classified according to type of accident. Incidence $=$ no of accidents/yrs of exposure to risk, in \%

\begin{tabular}{lcccc}
\hline & $45-54$ & $55-64$ & $65-75$ & $\begin{array}{l}\text { All } \\
\text { patients }\end{array}$ \\
\hline Placebo & & & & \\
Years of exposure to risk & 33.5 & 69 & 35.5 & 138 \\
Mortality (\%) & 9 & 4.3 & 5.6 & 7.2 \\
Recurrence (\%) & 15.0 & 10.1 & 0.0 & 8.7 \\
Other cardiovascular complications (\%) & 12.0 & 10.1 & 5.6 & 9.3 \\
Phenprocoumon & & & & \\
Years of exposure to risk & 46.5 & 73 & 48.5 & 168 \\
Mortality (\%) & 6.5 & 6.9 & 0.0 & 4.8 \\
Recurrence (\%) & 0.0 & 2.8 & 0.0 & 1.2 \\
Other cardivascular complications (\%) & 0.0 & 1.4 & 2.1 & 1.2 \\
\hline
\end{tabular}

TABLE XII. Number of cardiovascular complications classified according to length of pre-trial anticoagulant treatment

\begin{tabular}{|c|c|c|c|c|c|c|c|}
\hline & \multicolumn{6}{|c|}{ Length of anticoagulant treatment before trial (mos) } & \multirow[b]{2}{*}{$84-120$} \\
\hline & $12-23$ & $24-35$ & $36-47$ & $48-59$ & $60-71$ & $72-83$ & \\
\hline Re-infarctions & $3(1)$ & 3 & $4(1)$ & 1 & 3 & - & 一 \\
\hline Deaths & $7(3)$ & $3(1)$ & $1(1)$ & $2(2)$ & 2 & $4(1)$ & - \\
\hline $\begin{array}{l}\text { Other cardiovascular } \\
\text { complications }\end{array}$ & 5 & $1(1)$ & 3 & 2 & 2 & $2(1)$ & - \\
\hline
\end{tabular}

Numbers within brackets refer to patients belonging to the phenprocoumon group.

TABLE XIII. Evaluation of complaints as expressed by patients without definite cardiovascular complications. The feeling of improvement occurred significantly more often in patients on phenprocoumon than in patients on placebo $(\mathrm{p}<0.05)$

\begin{tabular}{lllll}
\hline & Improved & Unaltered & Worse & $\begin{array}{l}\text { Total no } \\
\text { of pats }\end{array}$ \\
\hline Phenprocoumon & $34.2 \%$ & $54.4 \%$ & $11.4 \%$ & 114 \\
Placebo & $19.3 \%$ & $65.8 \%$ & $14.5 \%$ & 76 \\
\hline
\end{tabular}


TABLE XIV. Evaluation of complaints as expressed by patients put back on phenprocoumon

\begin{tabular}{lcccc}
\hline & Improved & Deteriorated & $\begin{array}{l}\text { Un- } \\
\text { changed }\end{array}$ & Total \\
\hline $\begin{array}{l}\text { Phemprocoumon } \\
\text { Re-infarctions }\end{array}$ & - & - & 2 & 2 \\
$\begin{array}{l}\text { Other cardiovascular deterioration } \\
\text { Placebo }\end{array}$ & - & 1 & 1 & 2 \\
Re-infarctions & 1 & 5 & 5 & 11 \\
Other cardiovascular deterioration & 2 & 2 & 6 & 10 \\
\hline
\end{tabular}

complications was slightly more than nine times higher in patients on placebo $(24 \%)$ than in those on phenprocoumon (2.6\%).

Conspicuously enough, there is no correlation between the occurrence of accidents and the length of the pre-treatment period either for sudden deaths and re-infarctions or for other cardiovascular deteriorations. This becomes evident when the results shown in tables III and XII are tested together against trend in a $\mathrm{k} \times 2$ contingency table with approximation.

Between July 15 and Aug. 15, 1965, 190 of the 192 patients still included in the study were asked, under blind conditions, about their complaints at the end of the trial as compared to those before its start, especially cardiac symptoms. Table XIII summarizes the results of this interrogation. More of the patients treated with phenprocoumon than of those on placebo felt improved at the end of the trial (significant at a $5 \%$ level; test according to Yates and Cochran). Of the 29 patients who returned from the placebo group to anticoagulants because of re-infarction and other cardiovascular complications, 26 were still alive in Aug. 1965. Twenty-

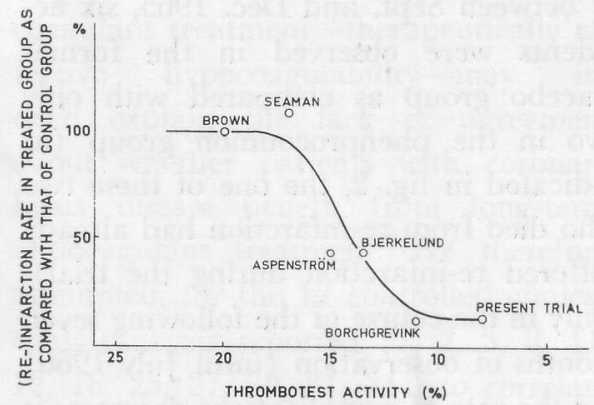

Fig. 4. Tentative curve of correlation between (re-)infarction rate and intensity of treatment, constructed upon data published or furnished by authors of controlled clinical trials.

five of them could be interrogated. Table XIV shows the results: almost one-third of the patients felt definite deterioration. Only three felt improved.

The results of the interrogation reinforce the evidence in favour of longterm anticoagulant treatment, although the patients' complaints are known to be the least objective criterion.

After discontinuance of the trial, although the daily number of tablets to be taken was not altered, the change in posology caused in some patients, irrespective of the type of drug they had been treated with, a transient increase of complaints similar to those observed immediately after the start of the trial. 
Patients who had been treated with placebo were checked a fortnight after the change of regimen. In most of them no important alteration in sensitivity to phenprocoumon appeared to have taken place. There were no important bleeding complications. Interestingly enough, however, as demonstrated in fig. 2, the rate of cardiovascular complications remained unaltered for about three months after discontinuance of the trial on Sept. 1: between Sept. and Dec. 1965, six accidents were observed in the former placebo group as compared with only two in the phenprocoumon group (as indicated in fig. 2, the one of these two who died from re-infarction had already suffered re-infarction during the trial). Only in the course of the following seven months of observation (until July 1966) did the rate of complications decrease; it then became similar for both groups. It should be emphasized that, during this second period of observation, no patient had been lost from observation, that there had been only one drop-out (due to a gastric ulcer) and that no severe bleeding complications were noted.

\section{Discussion}

The present study was undertaken in an attempt to decide whether it is worthwhile to continue long-term anticoagulant treatment for more than twelve months after a myocardial infarction, a question raised by Bjerkelund at the Toronto meeting in 1961 (4). We were fully aware that only a study satisfying the criteria of both a double-blind clinical trial and an adequate anticoagulant treatment could give us the answer.
From the design of our trial, described under Material and methods, it can be seen that the conditions of a doubleblind trial (13) are fulfilled: patients were known to be suitable for participation in the trial; allocation into phenprocoumon and placebo groups was made randomly; and the therapeutic regimen in both groups was the same except for the anticoagulant drug. However, as there was selection, i.e. exclusion of female patients, patients older than 75 and younger than 45 years, patients suffering from hypertension, patients physically unable to visit the laboratory of the Thrombosis Service, and patients with atrial fibrillation, etc., this selection could scarcely have biassed the structure of the two groups. Finally, the patients can be considered representative for Leiden and its surroundings because all the local cardiologists and internists follow the same line of treatment and refer all their patients to the Thrombosis Service for supervision of the anticoagulant treatment. With regard to the intensity and stability of the anticoagulant action (table IV, fig. 1), the conclusion seems warranted that most of the patients had received adequate treatment. In cases without contra-indications our aim was a stable hypocoagulability with thrombotest values between $5 \%$ and $10 \%$; as can be seen from fig. 1 , this was in the main achieved. In patients with relative contra-indications, coagulability was less uniformly depressed, as can be concluded from the larger standard deviation of the individual means. But in this group, too, values above $15 \%$ were exceptional.

Under these conditions the results 
obtained may indeed be regarded as relevant to the discussion of long-term treatment after myocardial infarction.

The difference in the rate of cardiovascular deaths $-4.8 \%$ in the phenprocoumon group as against $7.2 \%$ in the placebo group -is not significant. There is, however, a trend in favour of anticoagulant treatment. This becomes even more definite if this result is combined with the rate of cardiovascular deaths observed in a parallel trial, performed under very similar conditions in 144 patients suffering from peripheral sclerosis (17). In the latter study the figures were $2.3 \%$ (two deaths) in the phenprocoumon group against $9.5 \%$ (eight deaths) in the placebo group. Here, too, no correlation could be found between occurrence of death and length of the pre-treatment period. This suggests that unlimited long-term anticoagulant treatment in patients suffering from atherothrombosis prolongs life.

More obvious and undeniable is a reduction of morbidity. The difference between the two groups as to re-infarction rate and rate of other cardiovascular complications (important cardiac deterioration, dysbasia intermittens, cerebrovascular accidents), if considered with the statistical approach used by Bjerkelund (2), is highly significant. Phenprocoumon appears to provide a powerful protection against such events, especially in patients under 65 years of age (fig. 2, table XI). Moreover, the favourable effect appears to be independent of the duration of the anticoagulant treatment (table XII).

As far as we can judge from the literature, such favourable results in patients treated for more than twelve months have seldom been obtained in the past. This may be due to the exceptionally high intensity and good stability of hypocoagulability achieved in our patients. Although a similar quality of treatment is known to be required for effective prevention of the venous thromboembolic diseases (32), its necessity is not generally accepted for the prevention of arterial thrombosis.

Neglect of the specific aim of anticoagulant treatment - therapeutically effective hypocoagulability - may indeed explain the lack of agreement about whether patients with coronary heart disease benefit from long-term anticoagulant treatment. We therefore attempted, for the 12 controlled clinical trials thus far reported $(1,2,5,8,11$, $12,18,25,27,30,31,34)$, to correlate intensity of hypocoagulability with therapeutic success as measured by reduction of the re-infarction rate observed in coumarin-treated patients. The results of the five studies suitable for such an evaluation $(1,2,5,8,31)$ are shown in fig. 4 , in which the number of (re-) infarctions occurring in patients while on coumarin treatment is given as percentage of the number found in the control group. The interisity of treatment is expressed as grand mean of percentage values for thrombotest activity.

In evaluating data concerning hypocoagulability, we took into account that activities below $50 \%$ of normal found with the original P.P. method correspond to approximately $5 / 3$ of those found with the original thrombotest $(21,33)$, the difference being caused by preprothrombin, a circulating anticoagulant appear- 
ing in the circulation during coumarin treatment (19).

The only investigators who seem to have reached an intensity of treatment closely resembling ours, at least as far as patients treated with phenprocoumon are concerned (15), are Clausen et al. (11). These authors achieved a considerable reduction of the rate of recurrence in patients younger than 55 years limited to the first year of treatment. However, the importance of this result is difficult to assess because insufficient data are given as to the comparability of the coumarin and placebo groups. The results, therefore, are excluded from fig. 4 .

The rather strong hypocoagulability instituted by Borchgrevink (5) in patients suffering from angina pectoris receiving intensive treatment with phenindione was accompanied by very favourable clinical results. The mean P.P. activity was $19 \%(=11.4 \%$ thrombotest activity); only about onefifth of the values exceeded $25 \%$ P.P. activity ( $=15 \%$ thrombotest activity). Entirely negative results were obtained in patients treated during a supplementary period of observation when the mean thrombotest value was $19 \%$ (6).

Authors who have achieved moderate intensity and stability of coumarin action appear to have obtained partially favourable results. Bjerkelund (2, 3, 4) concluded from his study that long-term treatment with dicoumarol is primarily indicated in the younger age-groups $(<60$ years old men), and that the effect achieved during the first 12 months seems not to be lost after gradual cessation of therapy. In this first report Bjer- kelund gives figures from which a mean P.P. activity of about $23 \%(=13.8 \%$ thrombotest activity) can be calculated (2). Detailed figures indicate reasonable stability of treatment.

Similar conclusions hold for the British Medical Research Council (B.M.R.C.) trial $(27,28)$ in which phenindione had been the drug of choice, although it is difficult to convert prolongation of prothrombin time into percentage thrombotest; for acetonedried human brain thromboplastin, which was used by the authors of the B.M.R.C. trial, the prolongation sought, 2-2 $1 / 2$ times normal, probably corresponds to 5-12\% thrombotest percentage. Unfortunately, exact figures concerning intensity of treatment are not given. There is, however, the interesting finding of insufficient hypocoagulability (prothrombin time $<2$ times normal) both during the trial and before death in about $50 \%$ of the patients who died of re-infarction or other cardiovascular causes, whereas in survivors this percentage was only one-third. The high percentage of insufficient hypocoagulability demonstrates the rather low stability of treatment achieved in the British trial.

An equally positive result was obtained in the Veterans Administration (V.A.) study (34): treated and untreated patients differed significantly both in survival $(0.05>p>0.01)$ and in re-admission for cardiac infarction and congestive heart failure $(p<0.01)$. Prothrombin activity in treated patients seems to have been effectively reduced, for with use of human brain thromboplastin over $80 \%$ of the values were 
below $20 \%$. This corresponds to a prolongation of the prothrombin time of more than twice the normal (for human brain thromboplastin, $20 \%$ prothrombin activity equals a thrombotest value of about $12 \%$ ).

Aspenström and Korsan-Bengtsen (1) conclude from their double-blind study with dicoumarol and placebo that it is especially poor-risk patients who benefit from long-term prophylaxis. The intensity of coumarin was comparable to that of Bjerkelund, the mean P.P. value being $23 \%$ (personal communication), which corresponds to $13.8 \%$ thrombotest.

A less intensive anticoagulant treatment with phenindione, as applied by Seaman et al. (31), did not produce favourable results. These authors achieved a mean P.P. activity of $28 \%$ (=16.8\% thrombotest activity), about half of the values being higher than $25 \%$ P.P. activity (= higher than $15 \%$ thrombotest activity).

The completely negative result obtained with dicoumarol by Brown et al. $(8,9)$ accompanied a grossly insufficient anticoagulant effect; in a random sample, $67 \%$ of the thrombotest values were found to lie between $10 \%-30 \%$ and even as much as $6 \%$ higher than $30 \%$. Moreover, the high incidence of bleeding complications observed by these authors suggests a low stability of hypocoagulability. The negative reports of Lovell et al. $(24,25)$ and Conrad et al. (12) are irrelevant to the present discussion because the former give insufficient and the latter no information at all concerning intensity of treatment. Likewise difficult to assess are the results reported by Harvald et al. (18), because the requirement of random allocation does not seem to have been fulfilled (the placebo group is much larger than the phenprocoumon group) and no detailed figures concerning intensity or stability of treatment are given.

Convincing confirmation of the correctness of our reasoning concerning the correlation between intensity of anticoagulant treatment and the improvement (fig. 4) has been found in the report of a controlled clinical trial performed by Rozenberg et al. (30). In this trial, patients suffering from ischaemic heart disease, in whom it was attempted to maintain between $7 \%$ and $12 \%$ thrombotest activity, did significantly better than those within the $10 \%-20 \%$ range.

A decision on whether intensity of treatment is crucial calls for more trials performed under the conditions of our study. In our view, intensity and stability of the coumarin action can be achieved easily and safely, provided that a longacting coumarin preparation is used and that the patients are carefully supervised. An institution such as the organization of the Netherlands Thrombosis Service, in which the members of the staff (physicians and nurses) are fully responsible for the coagulation check, and an adequate dosage of the coumarin drug (20, 22, 23) may be pre-requisites.

\section{Summary and conclusion}

A double-blind clinical trial of long-term anticoagulant therapy after myocardial infarction was performed over $16 \quad 1 / 2$ months at the Thrombosis Service of Leiden. Phenprocoumon and placebo were the drugs of choice. Included in 
the study were 250 male out-patients, aged from 45 to 75 , who had been treated with phenprocoumon for at least 12 months before the start of the trial. The therapeutic regimen in both groups was the same except for the anticoagulant drug.

The incidence of cardiovascular deaths in the phenprocoumon group was $4.8 \%$ as against $7.2 \%$ in the placebo group. This difference is not statistically significant. The number of re-infarctions and the number of other important cardiovascular complications, however, were both much lower in the phenprocoumon group, the difference being significant at a $1 \%$ level. The two younger age-groups seem to have benefitted from phenprocoumon treatment more than the eldest group. The rate of occurrence of complications was independent of the length of pre-treatment with phenprocoumon.

The favourable clinical results are based upon a high and stable intensity of hypocoagulability. The mean thrombotest activity was $7.5 \%$ and $8.2 \%$ in patients without and with relative contra-indications respectively, the standard deviation of the individual means being $1.25 \%$ and $1.48 \%$. Less than $6 \%$ of the thrombotest values were higher than $15 \%$.

Despite such intensity of treatment, the frequency and the severity of bleeding complications were low. The rate of notable bleedings was roughly one per ten patient-treatment years; during the 168 patient-years of treatment, vitamin $\mathrm{K}_{1}$ was used only three times, and phenprocoumon treatment had to be discontinued only once because of a bleeding complication. No blood transfusions were given and no lethal bleedings occurred (the patient who died of cerebral haemorrhage belonged to the placebo group).

A comparative study of our results and of those published earlier strongly suggests that the extent to which recurrent coronary thrombosis is prevented by anticoagulant treatment depends primarily on the intensity of hypocoagulability achieved. Moderate hypocoagulability (thrombotest values $12 \%-25 \%$ ) is of limited or no value, whereas a sufficiently intensive treatment (thrombotest values of $5 \%-12 \%$ ) appears to improve the prognosis of coronary heart disease for an unlimited period of time, at least in ambulant male patients under 65 years of age. The achievement of a sufficiently intensive and stable hypocoagulability may depend, however, on tight supervision of the patients, such as is provided by the organization of the Netherlands Thrombosis Service, and on the use of phenprocoumon for its conspicuously prolonged anticoagulant effect.

\section{References}

Aspenström, G. \& Korsan-Bengtsen, K.: A double-blind study of dicumarol prophylaxis in coronary heart disease. Acta med. scand. 176: 563, 1964.

BJerkelund, C. J.: The effect of longterm treatment with dicoumarol in myocardial infarction. Acta med. scand. Suppl. 330: 1, 1957.

3. Bjerkelund, C. J.: Myocardial infarction. In: T. Astrup (ed.): Proc. 6th Congr. Europ. Soc. Haemat. p. 27. Karger, Basel and New York 1958.

4. BJerkelund, G. J.: The effectiveness of anticoagulant prophylaxis after myocardi- 
al infarction. In: Anticoagulants and fibrinolysins. R. L. MacMillan and J. F. Mustard (eds.). p. 266. Lea \& Febiger, Philadelphia 1961.

Borghgrevink, C. F.: Long-term anticoagulant therapy in angina pectoris and myocardial infarction. A clinical trial between intensive and moderate treatment. Acta med. scand. Suppl. 359: 52, 1960.

6. Borghgrevink, C. F.: Long-term anticoagulant therapy in angina pectoris. A follow-up study. Lancet 1: 449, 1962.

7. Brambel, E. \& Serra, G. L.: Oral anticoagulant therapy and its control: Marcoumar (phenprocoumon), a new highly active anticoagulant and Konakion (phytomenadione), as an effective regulator. Thrombos. Diathes. haemorrh. (Stuttg.) 3: 271, 1959.

8. Brown, K. W. G., MagMillan, R. L. \& Noble, E. J. G.: Failure of anticoagulant prophylaxis after myocardial infarction. In: Anticoagulants and fibrinolysins. R. L. MacMillan and J. F. Mustard (eds.). p. 259. Lea \& Febiger, Philadelphia 1961.

9. Brown, K. W. G. \& MacMillan, R. L.: Anticoagulant therapy in coronary artery disease: A therapeutic enigma. Canad. med. Ass. J. 92: 70, 1965.

10. Cladusen, J., Andresen, P., Gruelund, S., Harsløf, E., Andersen, U. H., JørgenSen, J. \& Mose, G.: Über die Verwendung von Marcoumar and Dicumarol bei der Langzeitbehandlung (vergleichende Untersuchungen). Thrombos. Diathes. haemorrh. (Stuttg.) 6: 37, 1961.

1. Claunsen, J., Andersen, P. E., Andresen, P., Gruelund, S., Harsløf, E., AnderSen, U. H., Jørgensen, J. \& Mose, C.: Studies on long-term anticoagulant therapy after coronary occlusion. Ugeskr. Læg. 123: 987, 1961.

12. Conrad, L. L., Kyriagopoulos, J. D., Wiggins, C. W. \& Honick, G. L.: A double-blind study of the effectiveness of long-term anticoagulant therapy in myocardial infarction. In: Anticoagulant therapy in ischemic heart-disease. E. S.
Nichol (ed.). p. 221. Grune \& Stratton, London and New York 1965.

13. Douglas, A. S.: Anticoagulant therapy. Blackwell, Oxford 1962.

14. Erkelens, A. D.: Die Prognose des Herzinfarktes. Lebensversicher. Med. 14: 31, 1962.

15. Frøland, A.: Studies on dosage prophylactic coumarin treatment of patients with coronary occlusion. Acta med. scand. 169: 545, 1961.

16. Gussenhoven, G. A.: De toepassing van orale anticoagulantia bij afwijkingen van de kransslagaderen. Ned. T. Geneesk. 105: 2260, 1961.

17. Hamming, J. J., Hensen, A. \& Loeliger, E. A.: The value of long-term coumarin treatment in peripheral sclerosis (clinical trial). To be published.

18. Harvald, B., Hilden, T. \& Lund, E.: Long-term anticoagulant therapy after myocardial infarction. Lancet 1: 626 , 1962.

19. Hemker, H. C., Veltkamp, J. J., HenSEN, A. \& Loeliger, E. A.: Nature of prothrombin biosynthesis: preprothrombinaemia in vitamin $\mathrm{K}$ deficiency. Nature 200: 589, 1963.

20. Jordan, F. L. J.: Organization of the "Thrombosis Service" in the Netherlands. Thrombos. Diathes. haemorrh. (Stuttg.) 2: 527, 1958.

21. Loeliger, E. A.: Unpublished results.

22. Loeliger, E. A.: Der Holländische Thrombosedienst, eine Lösung des Problems der Durchführung der exakt kontrollierten Coumarinbehandlung in der Praxis. Wien. klin. Wschr. 73: 917, 1961.

23. Loeliger, E. A. \& Hensen, A.: Die Organisation des Holländischen Thrombosedienstes. In: Langzeitbehandlung mit Antikoagulantien. L. Zukschwerdt and H. A. Thies (eds.) Thrombos. Diathes. haemorrh. (Stuttg.) Suppl. 12: 21, 1964.

24. Lovell, R. R. H.: Some sequels to myocardial infarction and their treatment. Brit. Med. J. 2: 465, 1964.

25. Lovell, R. R. H., Denborough, M. A., Nestel, P. J. \& Goble, A. J.: Phen- 
procoumon and heparin after myorcardial infarction. Arch. intern. Med. 113: 267, 1964.

26. MaMrahael, J. \& Parry, E. H. O.: Prognosis and anticoagulant prophylaxis after coronary occlusion. Lancet 2: 991 , 1960.

27. Report of the working party on anticoagulant therapy in coronary thrombosis to the Medical Research Council. An assessment of long-term anticoagulant administration after cardiac infarction. Brit. med. J. 1: 803, 1959.

28. Report of the working party on anticoagulant therapy in coronary thrombosis to the Medical Research Council (2nd report). An assessment of long-term anticoagulant administration after cardiac infarction. Brit. med. J. 2: 837, 1964.

29. Rodman, T., Pastor, B. H. \& Resnick, M. E.: Phenprocoumon, diphenadione, warfarin, and bishydroxycoumarin: A comparative study. Amer. J. med. Sci. 247: 655,1964 .
30. Rozenberg, M. C., Kronenberg, H. \& FIRkIN, B. C.: "Thrombotest" and prothrombin time: A controlled clinical trial. Aust. Ann. Med. 14: 3, 1965.

31. Seaman, A. J., Griswold, H. E., Reaume, R. B. \& Ritzman, L. W.: Prophylactic anticoagulant therapy for coronary artery disease. A seven-year controlled study. J. Amer. med. Ass. 189: 183, 1964.

32. Sevitt, S. \& Innes, D.: Prothrombintime and thrombotest in injured patients on prophylactic anticoagulant therapy. Lancet 1: 124, 1964.

33. Tat, R. J. \& Lewis, A. E.: Levels of equivalence for various measurements of coumarin activity. J. Amer. med. Ass. 180: 744, 1962.

34. Veterans Administration Study on longterm anticoagulant therapy after myocardial infarction. A study of 747 patients in 15 hospitals. J. Amer. med. Ass. 193: 929,1965 . 